\title{
A Model for Assessing the Development of Students' Creativity in the Context of Problem Posing
}

\author{
Atara Shriki \\ Oranim Academic College of Education, Tivon, Israel \\ Email: atarashriki@gmail.com
}

Received April 19 $9^{\text {th }}, 2013$; revised May 20 ${ }^{\text {th }}, 2013$; accepted May $27^{\text {th }}, 2013$

\begin{abstract}
Copyright (c) 2013 Atara Shriki. This is an open access article distributed under the Creative Commons Attribution License, which permits unrestricted use, distribution, and reproduction in any medium, provided the original work is properly cited.
\end{abstract}

\begin{abstract}
In a changing technological society, creativity is recognized as the vehicle of economic and social growth. Although the education system has a central role in developing all students' creativity, it is not often nurtured in schools. Several conditions are offered to justify this situation, among them: external pressures to cover the curriculum and succeed in standardized tests that generally require rote implementation of rules and algorithmic thinking; teachers' tendency to teach similarly to the way they themselves were taught as school students; relating creativity to giftedness, and therefore avoiding nurturing all students' creativity; teachers' difficulties in assessing their students' creativity and its development due to a lack of an available simple tool; and more. This paper is aimed at responding to the latter condition, suggesting a coherent and accessible tool or model for assessing students' creativity and its development in the context of problem posing. The proposed model considers 4 measurable aspects of creativity-fluency, flexibility, originality and organization, and a total score of creativity that is based on relative weights of each aspect. Viewing creativity as relative, the scores for these 4 aspects reflect learner's achievements in relation to his or her reference group. The proposed model has two flexible components- the first relates to teachers' interpretation of originality, and the second relates to the weights they may wish to ascribe each aspect of creativity. In addition, it is suggested to provide learners with a graphical display of their scores and progress in order to enable them to refine their products in successive iterations. The examples in this paper are taken from mathematics; however the proposed model can be adapted to any other discipline.
\end{abstract}

Keywords: Evaluation of Creativity; Problem Posing; The "What-If-Not?" Strategy; Self-Assessment of Creativity

\section{Introduction}

Creativity is generally perceived to be a key driver of social and economic changes. One would, therefore, anticipate that the education system would strive to nurture students' creativity (Beghetto, 2006). However, although teachers believe that mathematical creativity can and should be nurtured in school in most schools it is normally not encouraged (Sriraman, 2005). As a result most students are provided with few opportunities to experience creative learning and thinking (Silver, 1997).

This reality is a result of a combination of several circumstances, among them: (i) Teachers are subjected to various external pressures, such as covering the written curriculum, and help their students to succeed on both teacher generated and standardized tests (Beghetto, 2006). The education system emphasizes the importance of achieving high test scores, and too often teachers are judged based solely on their students' success on these tests. For the most part, standardized tests generally require rote implementation of rules and algorithmic thinking. Furthermore, standardized tests are not designed to formally assessing mathematical creativity (Chamberlin \& Moon, 2005). As a result, teachers tend to focus on memorization and algorithms, rather than on nurturing students' creativity; (ii) Teachers are inclined to teach similarly to the way they themselves were taught at school (Hall, Fisher, Musanti, \& Halquist, 2006). As school students, most of them experienced mathematics education that did not place an emphasis on developing creativity. With insufficient role models in their formative years of schooling to draw upon as positive examples, it is reasonable to assume that, as teachers, they may not have naturally acquired sufficient tools and methods aimed at nurturing students' creativity. Further exacerbating the problem is a shortage of appropriate learning materials, which makes it difficult for teachers to sustain learning environments that nurture creativity (Silver, 1997); (iii) Specifically to mathematics, there is a problem that stem from teachers' beliefs that creative thinking is not expressed across the curriculum, but is restricted to liberal arts and humanities. In their minds, examples of creative outcomes refer mainly to drawing, painting, writing and acting (Andiliou \& Murphy, 2010), viewing mathematics as offering fewer opportunities for creativity; (iv) Many teachers relate creativity to giftedness, and therefore avoid nurturing all students' creativity (Aljughaiman \& Reynolds, 2005; Sriraman, 2005); (v) Teachers face difficulties in assessing their students' creativity and its development due a lack of an available simple tool and therefore unable to implement a systematic approach to develop students' creativity (Shriki, 2010).

This paper is based on two main premises: (i) Nurturing stu- 
dents' creativity is not only possible at all ages and ability levels, but that it should be an integral part of the regular disciplinary curriculum; (ii) Providing teachers with a practical tool for nurturing students' creativity and assessing their progress might inspire them to integrate appropriate activities in their regular teaching. Given this stance, I plan to offer a model for assessing the development of students' creativity in the context of inquiry assignments that have a component of problem posing. The problem posing approach encourages students to ask questions, explore a range of answers, and develop a critical perspective. It is also considered to be strongly associated with fostering creativity. The model being suggested uses four measurable aspects of creativity: fluency, flexibility, originality, and generalization. In addition, I intend to show that teachers' and students' self-assessment of their own progress in each of these aspects contributes to their development of creativity in the context of problem posing. All the examples in this paper are taken from mathematics, as well as some specific references to mathematics education; however, the proposed model can be adapted to every other discipline.

\section{A Brief Literature Background}

Interest in fostering creativity in modern education first surfaced in the 1950's (Craft, 2001). The topic has garnered significant worldwide attention since the late 90 's, leading some to suggest that creativity has gained acceptance as a catalyst for social and economic change (Lin, 2011). In as much as creativity is considered essential for future success in life (NACCCE, 1999), it is incumbent upon teachers to create stimulating learning environments that are likely to nurture students' creativity. Indeed, research has acknowledged the fundamental role of education in nurturing students' creativity as part of its wider responsibility to instill content knowledge (Lin, 2011). As a result, educators have shown interest in exploring and enhancing creativity (Henry, 2009); assume that creativity can be developed through explicit instruction (Fryer, 1996); and that all students possess an innate sense of creative, given that they have a natural curiosity for trying out new things (Feldman \& Benjamin, 2006). Turning specifically to mathematics, it is believed that genuine mathematical activities are closely related to creativity (Silver, 1997), and developing students' mathematics creativity ought to be one of the primary goals of mathematics education (NCTM, 2000).

In this section I present a brief literature survey that relates to some common definitions of creativity and its relation to posing mathematical problems. I will then introduce the "What If Not?" (WIN) strategy as a means for posing new mathematical problems based on a given problem. Finally, I will relate to students' gains from engaging in self-assessment of their own products.

\section{Creativity}

Creativity "seems to be one of those words that although commonly used is not easy to define. We may use the term regularly, but can struggle if asked to put into words specifically to what we are referring" (Henry, 2009: p. 200). Educational and psychological researchers have explored the nature of creativity for more than a century (Plucker, Beghetto, \& Dow, 2004). This has resulted in a wealth of research aimed at understanding, explaining, and assessing the development of creativity over the years (Andiliou \& Murphy, 2010) and examining its source and expression in human experience (Silver, 1997). Furthermore, there are over one hundred contemporary definitions of creativity (Mann, 2006). Most of these definitions are vague or inadequate due to the multifaceted nature of creativity (Sriraman, 2005) and none are universally accepted (Treffinger, Young, Selby, \& Shepardson, 2002). Adding to this complexity, Henry's (2009) literature review indicates that creativity has been researched through the lens of, at least, four different perspectives: the creative process, the creative person, the creative environment, and the creative product.

Drawing on Torrance's (1974) definition of creativity, in the context of this paper I refer to four of its aspects: fluency, flexibility, novelty (or originality), and organization. "Fluency refers to the number of ideas generated in response to a prompt; flexibility to apparent shifts in approaches taken when generating responses to a prompt; and novelty to the originality of the ideas generated in response to a prompt" (Silver, 1997: p. 97). Organization refers to the number of generalizations (Brandau \& Dossey, 1979). Of the four aspects listed in Torrance's definition of creativity, novelty or originality is widely acknowledged as the most appropriate aspect because creativity is generally viewed as a process related to the generation of original ideas, approaches, or actions (Leikin, 2009; Shriki, 2010).

\section{Problem Posing and Nurturing Students' Creativity}

In order to support the development of students' mathematical creativity, mathematics educators should view creativity as "an orientation or disposition toward mathematical activity that can be fostered broadly in the general school population." For that matter, teachers should implement "inquiry-oriented mathematics instruction which includes problem-solving and problemposing tasks" (Silver, 1997: p. 75). Refraining from developing students' mathematical creativity might lead them to perceive mathematics as a set of skills and rules to memorize and cause them to lose their natural curiosity and interest in mathematics (Mann, 2006).

While contemporary views of creativity differ with respect to the nature of the trait and to the ability of individuals to produce creative outcomes, there is a growing consensus regarding the centrality of problem posing and problem solving processes within the creative act (Silver, 1997). According to Silver, problem posing has long been viewed "as a characteristic of creative activity or exceptional talent in many fields of human endeavor" (p. 76). Supporting his argument, Silver maintains that although mathematicians may solve problems that have been posed by others, they generally formulate their own problems based on personal experiences and interests. Indeed, Albert Einstein believed that "The formulation of a problem is often more essential than its solution, which may be merely a matter of mathematical or experimental skills. To raise new questions, new possibilities, to regard old questions from a new angle, requires creative imagination and marks real advance in science" (Einstien \& Infeld, 1938, in Ellerton \& Clarkson, 1996: p. 518).

However, this perception stands in stark contrast to schoolbased mathematics where, in most cases, problems are presented by teachers and in textbooks. Therefore, in order to develop students' mathematical creativity, teacher should engage their students in activities that include problem posing and provide them with developmentally appropriate, high interest opportunities to pose their own problems and suggest solutions (Mann, 
2006). As students pose their own problems, they become innovative, creative, active learners. They improve their reasoning, develop diverse and flexible thinking, and enrich and strengthen their knowledge and problem solving skills. Some have suggested that they might even change their perception of mathematics (Brown \& Walter, 1990), as well as increase their ability with respect to the central aspects of creativity: fluency, flexibility, originality and organization (Silver, 1997).

Problem posing involves generating new problems and questions aimed at exploring a given situation, as well as the reformulation of a problem over the course of its solution (Silver, 1994). This can be done by varying and reversing the "knowns" or givens, or by varying the constraints of the problem (Martinez-Cruz \& Contreras, 2002). When faced with new and novel mathematical situations, students are required to validate their thinking and selection of mathematical concepts used to generate their answers, thus leading them to develop and deepen their mathematical knowledge. When students formulate new problems, they develop a sense of ownership over the subject matter, which results in an increase of curiosity in and enthusiasm for learning mathematics (Cunningham, 2004).

\section{Employing the “What-If-Not?” Strategy for Posing Problems}

In order to enable students to generate mathematical problems, Silver (1997) suggests employing the instructional approach developed by Brown and Walter $(1969,1990)$, often termed as the "What-If-Not?" strategy. This method of instruction requires students to generate new problems based on previously solved problem, through a process of varying the conditions or goals of the original problem (Silver, 1997). By implementing this approach, teachers are likely to support the development of students' creativity in mathematics.

The "What-If-Not?" (WIN) strategy suggested by Brown and Walter $(1969,1990)$ is based on the idea that modifying the components of a given problem can yield new and stimulating problems that ultimately may result in some interesting investigations and may lead to the uncovering of mathematic regularities. This approach to problem posing leads the students through three levels of inquiry, starting with a re-examination of a given problem, in order to discover new related problems. In the first phase, students are asked to produce a list of the problem's attributes or conditions. In the second phase, students focus on each attribute in the list, address the WIN question, and suggest alternatives to the attributes. The third phase consists of posing new problems and questions based on the alternatives that arose during the second phase. Going through these phases students may develop new perspectives: "Only after we have looked at something, not as it 'is' but as it is turned inside out or upside down, do we see its essence or significance" (Brown \& Walter, 1990: p.15). Implementing the WIN strategy enables teachers to expand their teaching repertoire, thereby generating learning environments that encourage discussion of various ideas and demonstrate to students that there is often more than one "right way" to solve a given problem. This approach also enables students to consider the meaning of a problem, rather than simply focusing on finding its solution.

According to Haylock (1986), mathematical assignments should include problem posing, problem solving, and redefinition. The WIN strategy approach includes all three of these components. The first level, in which students list the attributes of a given problem, provides the opportunity to rethink mathematical objects and concepts. The second level, addressing the WIN question and suggesting alternatives, necessitates redefinition of mathematical situations. For that matter students have to consider the "logical contexts and conditions that underlie the determination of how to select certain givens and group them together in order to create a coherent mathematical situation" (Lavy \& Shriki, 2010: p. 19). The third level, posing new problems and questions and subsequently solving at least one of them, are closely connected to creativity (Silver, 1997).

\section{Evaluation of Creativity}

The activities of problem posing and the creative aspects of such activities-fluency, flexibility, novelty, and organizationare well established within the practice of assessing creativity. Both processes and products of activities that involve problem posing can be evaluated in order to determine the extent to which creativity is present. For that matter, it is possible to examine the novelty of the problem formulation or the problem solution, the extent to which modifications were evident, and the number of formulations or reformulations produced or the number of different solution paths investigated. Classifying creativity in terms of fluency, flexibility, novelty and organization also provides teachers with an easy schema for evaluating the trait (Brandau \& Dossey, 1979; Silver, 1997).

\section{Self-Assessment of Creativity}

The Standards of the NCTM (2000) recommend engaging students in self-assessment in order to nurture their confidence and independence in learning mathematics. Skills acquired though self-assessment are actually life skills that are applicable to a wide range of situations (Smith, 1997). Engaging students in self-assessment of attaining goals they set to themselves "allows students ownership over and responsibility for their learning as well as providing real choices about what they learn. It provides students with opportunities to spend time reflecting on their learning... through being engaged in self-assessment, students become deeply self-motivated and independent learners." (p. 7). Moreover, students' involvement in assessing their own progress in learning adds reflection and metacognition to their learning. Students enjoy participating in self-assessment and observing their progress using graphical displays, and are able to use it for articulating the value of their own study (Brookhart, Andolina, Meganzuza, \& Furman, 2004). Relating specifically to self-assessment of one's own creativity, Chamberlin \& Moon (2005) believe that such process in itself requires creativity and will, in return, enable students to refine their products in successive iterations. Therefore, it is recommended to enable students to assess their own creativity and its development. However, in order to help students assess their performance and progress, they should be provided with clear and easily understood guidelines (Enz \& Serafini, 1995), and they need to be taught how to self-assess themselves and get a proper support from their teachers (Brookhart et al., 2004). Research indicates (e.g. Enz \& Serafini, 1995) that after gaining a suitable training, students are able to keep the self-assessment with little or no assistance from their teacher, and students who are trained in selfassessment outperform their peers who do not receive such preparation. 


\section{A Model for Evaluating Creativity and Its Development in the Context of Problem Posing}

Considering the multifaceted nature of creativity, it is obvious that selecting a definition that embraces all mathematical areas or types of mathematical assignments would be impossible. In this current framework, the proposed model is intended to evaluate creativity and its development in the context of inquiry tasks that have a component of problem posing through relating to fluency, flexibility, originality, and organization. Drawing on Balka (1974), Brandau \& Dossey (1979), and Torrance (1974), fluency is measured by the number of different problems posed, flexibility is measured by the number of different categories of the posed problems, originality is measured by the relative infrequency of the problems, and organization is measured by the number of problems stated as generalizations. As pointed out by Brandau \& Dossey, all of these variables are highly significant and positively correlated.

The view of personal creativity, as a quality that can be developed in school students, requires a distinction between relative and absolute creativity (Leikin, 2009; Sriraman, 2005). While absolute creativity is associated with remarkable historical works of prominent mathematicians, relative creativity refers to discoveries made by a specific person within a specific reference group. This distinction is expressed in Leikin's (2009) model aimed at evaluating mathematical creativity in the context of multiple solutions to a given problem. Leikin (2009) suggested the notion of "solution spaces". She referred to "Expert solution spaces" as those "that include the most complete set of solutions to a problem known at a particular time", where in school mathematics "expert solution spaces include conventional solution spaces, which are those generally recommended by the curriculum, displayed in textbooks, and usually taught by the teachers. By contrast, unconventional solution spaces include solutions based on strategies usually not prescribed by the school curriculum, or that the curriculum recommends with respect to a different type of problem". "Individual solution spaces" are perceived as "collections of solutions produced by an individual to a particular problem"; and "Collective solution spaces" refer to the collection of all "individual solution spaces within a particular community” (Leikin, 2009: p. 133). Drawing on this distinction and adapting it to the context of problem posing, in the proposed model below each student receives a total as well as relative score of fluency, flexibility, originality and organization. The individual total score is equivalent to the meaning of "individual space", and the individual relative score refers to the frequency of a posed problem included in the individual space in relation to its frequency in the collective space, as will be explained below.

\section{Guidelines for Scoring the Four Aspects of Creativity}

The scoring process refers to the third level of the WIN strategy, where learners have to relate to the list of attributes they produced (first level) and their possible alternatives (second level) to pose new problems. In order to determine students' score for each aspect of creativity, and an overall creativity score, the following steps are applied:

\section{a. Fluency scoring}

Student's total score of fluency is determined by totaling the number of different new problems he or she posed, based on a given problem. The relative score of fluency is determined in the following manner: the student in the reference group who re- ceived the highest total score of fluency is given a score of 100 for relative fluency. All other students' relative scores of fluency are determined according to the highest score. For example, if the highest total score is 20 (namely, each student posed 20 different problems at the most), then those who posed 20 problems receive a relative score of 100 . Those who posed, for instance, 12 problems receive a relative score of 60 .

\section{b. Flexibility scoring}

Student's total score for flexibility is determined by the total number of different categories that are constituted by the posed problems. The relative score of flexibility is determined similarly to the relative score calculation used for fluency.

\section{c. Originality scoring}

Since originality is, by its very nature, relative there is a need to predetermine the condition for originality. If we take, for example, all the problems posed by a third of the students to be the "upper" limit for originality, then all students who posed problems that $33 \%$ or less of the students posed will receive a score for originality. Obviously, this "upper limit” can vary from one class to another. Other students will receive a score of 0 . The relative score of originality is determined in the following manner: Assume that the group consists of 30 students. In this case only problems that were posed by 10 or fewer students are considered for scoring originality. The students who posed the largest number of such problems receive a score of 100 for originality. Other students who posed problems that are considered for scoring originality receive a relative score similarly to the calculations used for scoring fluency and flexibility.

\section{d. Organization (or generalization) scoring}

Students' total score for organization is determined according to the number of posed problems that are formulated as a generalization, and then the relative score is calculated similar to the above cases.

\section{e. An overall total score of creativity}

Finally, the overall score of creativity is determined, assigning a weight for each of the four relative scores. Determining relative weighting is subjected to the teachers' discretion, according to the importance they ascribe to each aspect. Clearly, the beliefs teachers hold about creativity is likely to influence how they define, operationalize, and evaluate students' creativity (Andiliou \& Murphy, 2010). Therefore, it is important to provide teachers with the freedom to determine each component's weight, adapting it to their preferences, emphasizes and teaching goals.

\section{Demonstrating the Scoring Process}

In this section I demonstrate the scoring process, illustrating how to set the total and relative scoring for fluency, flexibility, and organization; the scoring for originality; and the final overall scoring for creativity. This demonstration is based on results taken from a study carried out by Lavy \& Shriki (2010). In this study, 25 prospective teachers were engaged in problem posing in geometry through implementing the WIN strategy. The given problem was taken from Hönsberger (1985: p. 81): Triangle $A B C$ is inscribed in circle $O . D$ is a variable point on the circumference of $O$. Perpendiculars are drawn from $D$ to $A B$ and AC. $E$ and $F$ are intersection points of the perpendiculars with the side of the triangle, respectively. Determine the position of $D$ whereby $E F$ is of maximal length. Based on this problem, the prospective teachers posed 46 different problems that were classified into 12 different categories. Each problem was as- 
signed a number indicating its category. For example, category no. 1 was "A polygon is inscribed in a circle". Namely, the only change related to the type of polygon inscribed in the circle. Four different alternative problems related to this category. These new problems were numbered accordingly: 1.1 A quadrangle is inscribed in the circle; 1.2 A square is inscribed in the circle; 1.3 A pentagon is inscribed in the circle; and $1.4 \mathrm{~N}$-sided polygon is inscribed in the circle. Problems 1.1, 1.2, 1.3, and 1.4 were posed by 25 prospective teachers $(100 \%), 20$ prospective teachers (20\%), 14 prospective teachers (56\%), and 4 (16\%) prospective teachers, respectively.

\section{Organizing the Data}

In order to "map" the prospective teachers' posed problems, Table 1 was generated. In the first line appears each prospective teacher's (PT) number (1 - 25). The left column in the grey part of the table is the number of each category (c.), 1 - 12, and in the second left column appears the number assigned for each problem that was posed in the particular category. For each PT a mark of "+" appears in case he or she posed the specific problem.

\section{Scoring Fluency, Flexibility, Originality, Organization, and Creativity}

\section{a. Scoring total and relative fluency}

For each PT, the number of problems he or she posed was counted, and this determined his or her total score of fluency (see Table 1-Flu, T.S). For example, PT1 posed 16 problems, thus
PT1's total score of fluency was 16. The relative score (R.S) of fluency was determined in the following manner: The PTs with the highest number of problems posed received a relative score (R.S) of 100 for fluency. Table 1 indicates that PT10 was the one who posed more problems than the other PTs (30 problems, T.S $=30$ ), and thus received a relative score of 100 . Other scores were determined relatively to PT10. For example, PT1, who posed 16 problems, received a R.S of 53 [round of (16/30) * 100]. Other R.S of fluency was calculated in a similar manner.

\section{b. Scoring total and relative flexibility}

For each PT, the number of categories his or her posed problems referred used for determining the total score of flexibility. For example, PT1 posed problems that corresponded 7 of the 12 categories, thus her total score of flexibility was 7.

The PTs with the highest number of categories to which their problems corresponded received a relative score of 100 for flexibility. From Table 1 we can see that PT16 posed problems that fitted in all 12 categories, and thus received a relative score of 100. Other R.S was determined relatively to PT16. For example, PT1's problems matched 7 categories, thus her relative score of flexibility was 58 [round of $(7 / 12) * 100$ ]. Other R.S. of flexibility was calculated in a similar manner.

\section{c. Scoring total and relative originality}

We shall now examine the two most right columns of Table 1, titled "Orig". For each problem that was posed, the number of PTs who posed it was counted and recorded in the second right column (titled “Tot”). For example, problem 1.1 was posed by all 25 PTs. The problem with the highest number of PTs who suggested it was indicated by " $100 \%$ ” (see the most right column

Table 1.

Data relating to the problem posed by each prospective teacher, according to categories; total and relative scores of fluency, flexibility, originality, and organization, and a score of overall creativity.

\begin{tabular}{|c|c|c|c|c|c|c|c|c|c|c|c|c|c|c|c|c|c|c|c|}
\hline & & & & & & & & & & & & & & & & & & \multicolumn{2}{|c|}{ Orig. } \\
\hline C. & $\mathrm{PT}$ & 1 & 2 & 3 & $\ldots$ & 10 & 11 & 12 & 13 & 14 & 15 & 16 & 17 & $\ldots$ & 23 & 24 & 25 & Tot & $\%$ \\
\hline \multirow{3}{*}{1} & 1.1 & + & + & + & $\ldots$ & + & + & + & + & + & + & + & + & $\ldots$ & + & + & + & 25 & 100 \\
\hline & 1.2 & + & + & + & $\ldots$ & + & + & + & + & + & + & + & + & $\ldots$ & & & & 20 & 80 \\
\hline & 1.3 & & & & $\ldots$ & & & + & + & + & + & + & + & $\ldots$ & + & + & + & 14 & 56 \\
\hline \multirow{2}{*}{2} & 2.1 & + & + & + & $\ldots$ & + & + & + & + & + & + & + & + & $\ldots$ & + & + & + & 25 & 100 \\
\hline & 2.2 & + & + & + & $\ldots$ & + & + & + & + & + & + & + & + & $\ldots$ & + & + & + & 25 & 100 \\
\hline$\vdots$ & $\vdots$ & $\vdots$ & $\vdots$ & $\vdots$ & $\vdots$ & $\vdots$ & $\vdots$ & $\vdots$ & $\vdots$ & $\vdots$ & $\vdots$ & $\vdots$ & $\vdots$ & $\vdots$ & $\vdots$ & $\vdots$ & $\vdots$ & & $\vdots$ \\
\hline \multirow{2}{*}{12} & & & & & $\ldots$ & & & & & & & + & + & $\ldots$ & & & & & 24 \\
\hline & 12.2 & & & & $\ldots$ & & & & & & & & & $\ldots$ & & & + & 1 & 4 \\
\hline Flue & R.S & 53 & 57 & 57 & $\ldots$ & 100 & 97 & 97 & 97 & 97 & 97 & 93 & 83 & $\ldots$ & 63 & 53 & 57 & & \\
\hline \multirow{2}{*}{ Flex } & T.S & 7 & 7 & 7 & $\ldots$ & 9 & 9 & 9 & 9 & 9 & 11 & 12 & 10 & $\ldots$ & 8 & 8 & 9 & & \\
\hline & R.S & 58 & 58 & 58 & $\ldots$ & 75 & 75 & 75 & 75 & 75 & 92 & 100 & 83 & $\ldots$ & 67 & 67 & 75 & & \\
\hline \multirow{2}{*}{ Orig } & T.S & 0 & 0 & 0 & $\ldots$ & 7 & 6 & 5 & 5 & 5 & 5 & 5 & 2 & $\ldots$ & 3 & 2 & 3 & & \\
\hline & R.S & 0 & 0 & 0 & $\ldots$ & 100 & 86 & 71 & 71 & 71 & 71 & 71 & 29 & $\ldots$ & 43 & 29 & 43 & & \\
\hline \multirow{2}{*}{ Org } & T.S & 0 & 0 & 0 & $\ldots$ & 1 & 1 & 2 & 2 & 1 & 1 & 0 & 0 & $\ldots$ & 1 & 0 & 0 & & \\
\hline & R.S & 0 & 0 & 0 & $\ldots$ & 50 & 50 & 100 & 100 & 50 & 50 & 0 & 0 & $\ldots$ & 50 & 0 & 0 & & \\
\hline \multicolumn{2}{|c|}{ Creativity } & 28 & 29 & 29 & $\ldots$ & 81 & 77 & 86 & 86 & 73 & 77 & 66 & 49 & $\ldots$ & 56 & 37 & 44 & & \\
\hline
\end{tabular}

$(\mathrm{PT}=$ prospective teacher, $\mathrm{c}=$ category, Flue $=$ fluency, Flex = flexibility, Orig = originality, Org = organization, T.S = total score, R.S = relative score $)$. 
of Table 1). Other problems were calculated relative to problem 1.1 (or other problems that were posed by all the PTs). For example, problem 12.1 was posed by 6 PTs, and thus was indicated by $24 \%[(6 / 25) * 100]$.

As mentioned, for scoring originality I arbitrarily chose to include only problems posed by a third or less of the prospective teachers. Namely, problems recorded in the most right column as “33\%" or less. In order to determine each PT's total score for originality, the number of problems posed that were indicated by " $33 \%$ " or less were counted. This constituted the total score for PT's originality (see Table 1-Orig, T.S). For example, PT1 did not pose any such problems, thus her T.S for originality was 0 .

The prospective teachers with the highest number of such problems received a relative score of 100 for originality. From Table 1 it can be seen that PT10 posed 7 problems that were suggested by less than $33 \%$ of the PTs. Her total score for originality was 7 and her relative score for originality was 100 . Other scores for relative originality were determined based on PT10's score. For example, PT12 suggested 5 such problems, thus her score of originality was 71 [round of $(5 / 7) * 100$ ]. Other scores of relative originality were calculated in a similar manner.

It should be noted that in Leikin's (2009) model originality was evaluated by comparing individual solution spaces with the collective solution space of the reference group based on the rarity of their solution, distinguishing between the types of solutions: those that were suggested by less of $15 \%$ of the students, those that were suggested by more than $15 \%$ but less that $40 \%$ of the students, and those that were suggested by more than $40 \%$ of the students. Each type of solution received a different score for originality. Therefore, in the case of the present proposed model teachers might wish to distinguish between the originality of the posed problems based on similar observation instead of adhering to one upper limit (e.g. 33\%), as suggested.

\section{d. Scoring total and relative organization}

The score for organization was assigned in accordance with the number of problems that were posed as generalizations. There were only 5 such problems (1.4, 5.6, 5.10, 8.2, and 9.2). Table 1 indicates that two PTs (PT12 and PT13) posed two generalized problems. Therefore, their total score for organization was 2 (Org, T.S) and their relative score for organization was 100 . Those who posed 1 generalized problem received a total score of 1 , and a relative score of 50 . The remainder received a total and relative score of 0 .

\section{e. Scoring overall creativity}

Finally, in order to assign a score for each prospective teacher's overall creativity, it is necessary to determine the relative weight of fluency, flexibility, originality and organization. As mentioned, the relative weight should reflect the importance teachers ascribe to each component, as well as their priorities, preferences, emphasizes given in class, and teaching goals. In this example, merely for a matter of simplicity, I arbitrarily assigned each component the same weight (25\%), namely a round of the sum of all R.Ss divided by 4 , as can be seen from the last row of Table 1.

\section{Inferring Information from the Scores}

As stated, teachers face difficulties in evaluating the creativity of their students and its development. As a natural consequence, questions arise when employing the model for assessing students' creativity and its development as well as interpreting the numerical results. The following are several suggestions. It should be noted that these suggestions are based on results obtained from two small-scale studies that were carried out throughout the design of this model (see below).

\section{Graphical Display of Data}

Graphical display of data can include various types of information. For example, the relative scores of every student in each of the four aspects of creativity, as well as the score for creativity; distribution of total and relative scores; and more. Bellow there are two examples, based on a complete version of Table 1 (Figures 1 and 2).

Based on such graphical displays teachers can get an idea about the strengths and weaknesses of each student as well as the entire class, and make some pedagogical decisions regarding the emphases they should put in order to nurture students' creativity. Similar displays can also describe cumulative results of a process that takes place over a prolonged time, in order to receive a feedback about the impact of their teaching.

\section{Evaluating the Development of Creativity}

Assuming that teachers engage their students in problem

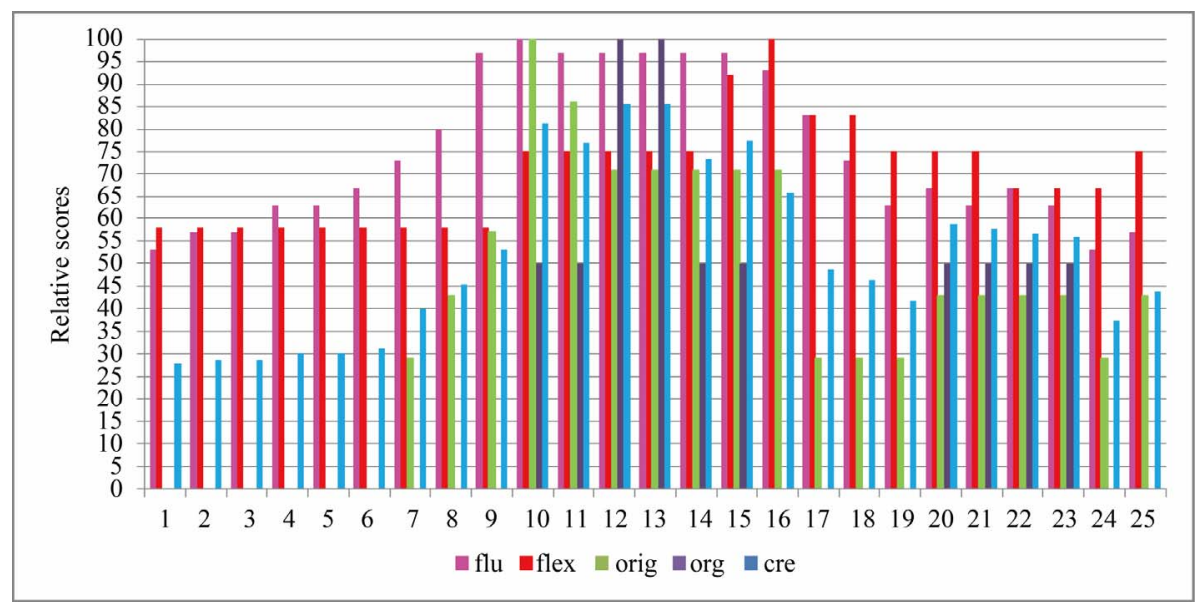

Figure 1.

Relative scores of every prospective teacher (1 - 25). 


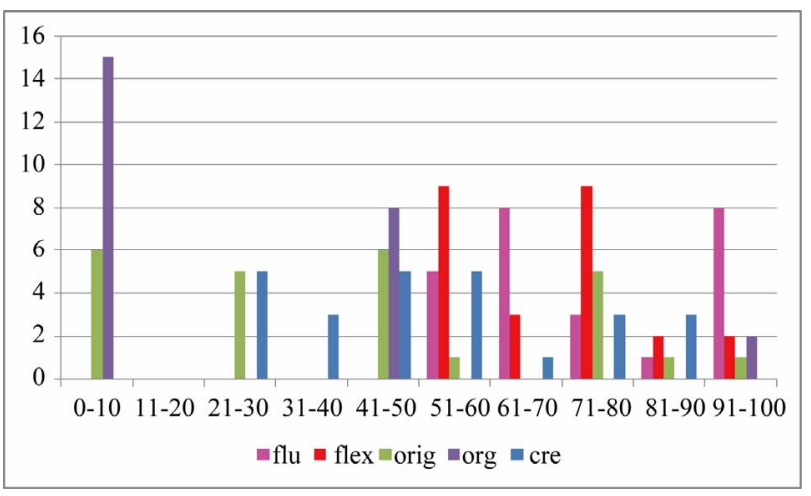

Figure 2.

Distribution of relative scores.

posing assignments for an extended period of time, how can teacher employ the proposed model for assessing the development of their students' creativity in order to make educational decisions? What indicators might serve this purpose?

The model allows producing the following four numerical values: total scores, relative scores, averages, and standard deviations. The strengths and weaknesses of these numerical values for making educational decisions are as follows:

\section{a. Total scores}

The total scores for fluency, flexibility, originality and organization cannot be used for assessing the development of creativity because the number of problems that can be posed through employing the WIN strategy, and the resulted categories, might depend on the richness of attributes that are embedded in the original problem. However, total scores might be used in cases where teachers wish to make comparisons between classes that work on the same problems. Such a comparison is valuable mainly when teachers wish to examine the impact of different approaches intended to engage their students in problem posing assignments, or compare between students learning at different levels of mathematics or different age groups with respect to the impact of engaging them in posing problems.

\section{b. Average relative scores}

In the case of relative scores, a significant increase in the average of any of the relative scores indicates that some students developed their creativity much more than others. In such cases, special attention might be given to students whose relative scores did not change much with time. Alternatively, it may indicate that creativity is indeed innate, and students that are more creative than other from the outset show a greater tendency to keep develop their creativity. Minor or no changes might imply that the entire class, as a reference group, either did not progress or all students exhibited similar progress (or regression).

\section{c. Standard deviations}

Assuming that practicing the WIN strategy over and over again will not cause a decrease in mathematical creativity, a decrease of standard deviation in any of the measures implies the development of creativity of the class as a whole. Obviously, this is the most desirable situation. Therefore, an increase or decrease in standard deviations should serve as a primary indicator for examining the development, lack of development, or perhaps a decrease of creativity attributed to the class as a group of reference. If indeed, creativity of all students can be developed through appropriate education, as suggested by the above men- tioned research literature, then we would expect a gradual reduction in standard deviations over time. However, a gradual increase in standard deviation might support theories that maintain that creativity is innate, and that only exceptional people can demonstrate creative behavior. It should be noted that in order to be able to track changes, there is a need to predetermine the "upper limit" used for scoring originality, as well as the weight of each component of creativity, and adhere it. Otherwise, tracing changes over time would be impossible.

\section{Some Insights Gained from Using the Model in Practice}

As mentioned, the proposed model was designed through carrying our two small-scale studies. In the first study 6 upperelementary mathematics teachers were engaged in a series of 5 problem posing activities employing the WIN strategy. All the initial problems were taken from common school textbooks in order to demonstrate the idea that problem posing can easily become an integral part of school curriculum. By the end of each activity the teachers presented their posed problems and together categorized the problems in order to gain an understanding about the meaning of categorization. In addition, the teachers analyzed the appropriateness of each posed problems (see below). Then I generated a table similar to Table $\mathbf{1}$, and each teacher received, personally, only the information that was relevant to his or her total and relative scores in a format of graphical display. Starting from the second activity the graphical display included cumulative scores (see example in Figure 3). This graphical display was intended to help the teachers trace their progress/withdrawal compared to his or her reference group. During the entire process the teachers documented their work in a reflective journal, and referred to aspects that concerned their perspective of themselves as learners of mathematics, their mathematical creativity, the pedagogical insights they had gained, and the role played by their ability to self-assess their progress/withdrawal.

In the second study each teacher repeated the process with one of his or her classes.

The results of these studies allowed formulating the proposed format of the model, and examine the effectiveness of the use of the model to track the development of each student's creativity, in all four aspects, as well as the entire class as a reference group.

Due to space limitations full results of these studies are not included in this paper; however I would like to shed light on some of the insights gained from them:

\section{Types of Problem Posing Situations}

In their study, Stoyanova and Ellerton (1996) suggest that every problem posing situation can be classified as free, semi-structured or structured. Problem posing situation will be referred to as free "when students are asked to generate a problem from a given, contrived or naturalistic situation. Some directions may be given to prompt certain specific actions" (p. 519); as semi-structured "when students are given an open situation and are invited to explore the structure and to complete it by applying knowledge, skills, concepts and relationships from their previous mathematical experiences"; and as structured "when problem-posing activities are based on a specific problem" (p. 520). The above mentioned studies indicated that the teachers found that it was easier to implement the WIN strategy within a structured problem posing situation, especially due to 


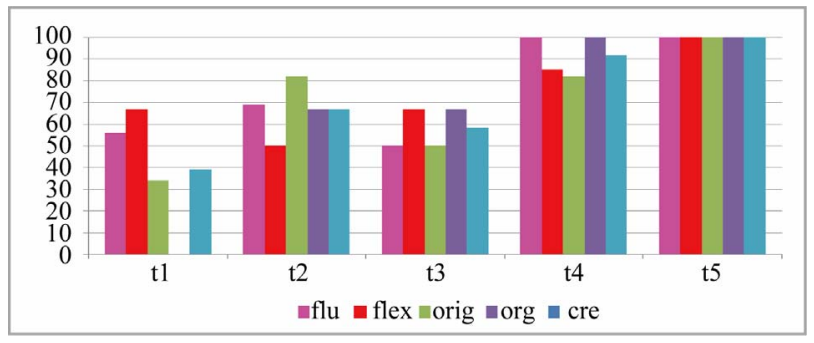

Figure 3.

An example of a personal graphical display of cumulative relative scores $(\mathrm{t}=$ task $)$.

lack of previous experience with posing mathematical problems. In their opinion, such situation generates "a firmer anchor to hang on". There is still, however, a need for a prolonged widescale study aimed at examining the impact of the type of situation on the development of students' creativity.

\section{Appropriateness of the Posed Problems}

There is one reservation concerning the "freedom" of posing new problems. Given that students are scored for fluency, the teachers noticed that they might be tempted to pose as many problems as possible, without considering their appropriateness. Inappropriate problems can have, for example, insufficient or irrelevant information. Namely, posing mathematical problem cannot stand as its own goal, and students must be explicitly instructed how to consider criteria such as appropriateness or correctness with regard to the requirements and constraints of the task (Andiliou \& Murphy, 2010), and not implement a watered down version of the approach in an effort to introduce "novel ideas."

\section{Discussing the Essence of Original Problems}

In order to develop students' appreciation to originality, the teachers found it important to present original problems that were posed by their fellow classmates, and spend time discussing and negotiating issues that concern the essence of these problems. In their opinion, such discussion might shed light on distinctions between "regular problems" and "original problems”, and, as suggested by Silver (1997), instruct students how to evaluate the novelty of a posed problem.

\section{Avoid Overemphasizing the Need to Solve the Posed Problems}

As mentioned, the WIN strategy can yield new and stimulating problems that ultimately may result in some interesting investigations. However, as evident from the first study mentioned above, overemphasizing the need to solve the problems that were posed might suppressed the willingness to pose, what might be regarded as a "revolutionary problem". In such cases, learners might hold back, concerned about their inability to solve the problems they themselves have posed (Lavy \& Shriki, 2010). Therefore, in order not to 'block' the flow of problems posed by students, teachers should instruct them not to worry about their inability to solve some of the problem; otherwise they might limit themselves to posing trivial problems. Instead, solving "difficult" problems might be done through a collaborative class effort.

\section{Students' Self-Assessment of Their Progress}

As mentioned, learners' self-assessment of one's own creativity enables them to refine their products in successive iterations (Chamberlin \& Moon, 2005). Indeed, as was evident from the teachers' and the students' reflective portfolios, the graphical displays of their gradual progress, as describe in Figure 3, was a powerful means that allowed them to reflect on their strengths and weaknesses as well as their progress over time, both relatively to their previous accomplishments and their reference group. It turned out that the use of the model and "translating” personal results into graphical display had a great impact on the teachers' and students' motivation to improve their fluency, flexibility and originality, as well as their drive to search for possible generalized problems.

\section{The Flexibility of the Model}

As mentioned, teachers are free to determine the upper limit for creativity as well as the relative weight of each component. In that sense, the model is rather flexible and actually enables teachers to adapt it to their teaching goals. As was evident from the first study mentioned above, the teachers attributed great importance to this flexibility. In their opinion organization, for example, should receive a low weight in cases where low achievers are engaged in problem posing, since they have difficulties in understanding the meaning of generalization. Originality, for example, should have a lower upper limit in classes of high achievers, in order to encourage them to pose unconventional problems. Therefore, as stated, it is important to leave the final decision in the hand of the teachers, allowing them to adjust the model to the target populations and their educational philosophy.

\section{Discussion and Conclusions}

In a changing technological society, innovations are recognized as the vehicle of economic and social growth and as essential to the welfare of all (Andiliou \& Murphy, 2010). Promoting these innovations necessitates creativity (Shalley \& Gilson, 2004). When taken to its logical conclusion, and viewing creativity and content knowledge as inseparable (Rowlands, 2011), this implies that the objective of education should not be limited to enhancing knowledge and skills, but also to nurturing creativity (Craft, 2009). However, creativity is not often nurtured in school (Sriraman, 2005). As has been mentioned in the introduction section, several conditions are offered to justify this situation. This complex set of perceived obstacles suggests that attention should be given, first and foremost, to modifying teachers' beliefs regarding the nature of creativity, as beliefs teachers hold regarding creativity are likely to influence the role they assume in relation to creative thinking as a learning objective, the instructional approach they implement for fostering students' knowledge and creative behavior in the subject matter being taught, and the evaluation procedures they apply in order to assess creative products (Andiliou \& Murphy, 2010). A first step towards achieve this goal is to assist teachers to view creativity as inherent in learning (Beghetto \& Kaufman, 2009), and inspire teachers to believe that all students can become creativeas creativity is not an exclusive trait of the gifted (Rowlands, 2011). However, in order for teachers' beliefs to translate into instructional practice, they have to establish the development of 
creative thinking as a discrete learning goal. In addition, attention should be given to strengthen teachers' ability and readiness to nurture students' creativity, and provide them with appropriate tools and pedagogic approaches aimed at supporting their capability to develop and assess students' creativity. All of this must be done while taking into account constraints such as coverage of the mandated curriculum and standardized testing outcomes.

Although contemporary views of creativity differ with respect to the nature they ascribe to creativity and to the ability of individuals to produce creative outcomes, there is a growing consensus regarding the centrality of problem posing and problem solving processes within the creative act (Silver, 1997).

In order to enable students to generate their own mathematical problems, Silver (1997) suggests employing the three-phase WIN instructional approach developed by Brown and Walter (1969, 1990). The third phase, posing new problems and questions and subsequently solving at least one of them, are closely connected to creativity (Silver, 1997). By implementing this approach, teachers are likely to support the development of students' creativity in mathematics. In addition, by discussing the posed problems students learn to evaluate the novelty of a problem. According to Haylock (1986), mathematical assignments should include problem posing, problem solving, and redefinition. The WIN strategy approach includes all three of these components. Therefore, it appears that implementing this approach systematically in classes might satisfy both developing students' mathematical creativity and effectively respond to the need to adhere to curricular demands within specific time limitations. Namely, the WIN approach guarantees that nurturing creativity does not come at the expense of teaching the subject matter, but rather completes it. For that matter, instead of asking students to solve 10 different problems that do not have anything in common, teachers might ask students to solve 10 different problems that can be derived from the same mathematical situation. In return, arriving at conclusions and identifying generalizations will strengthen students' mathematical and metamathematical knowledge (Lavy \& Shriki, 2008; Shriki, 2010).

In this paper I suggest a model for assessing students' creativity and its development in the context of problem posing, with the aim to respond teachers' need for having a coherent and accessible tool to serve this purpose (Shriki, 2010). Reid and Petocz (2004) state that "it is a fairly difficult exercise to discern what is meant by the term 'creativity', or to decide what may be interpreted as a 'creative' object, or to describe the cognitive traits that characterize a 'creative' person" (p. 46). Therefore, the proposed model is based on measurable aspects of creativity, namely-fluency, flexibility, novelty and organization (Torrance, 1974; Silver, 1997). Viewing personal creativity as a quality that can be developed in school students, there is a need to distinguish between relative and absolute creativity (Leikin, 2009). Thus, in the proposed model, each student receives a total as well as relative score of fluency, flexibility, originality and organization. As teachers' beliefs about creativity influence how they define, operationalize, and evaluate students' creativity (Andiliou \& Murphy, 2010), it is important to let teachers decide what they perceive as the meaning of "originality" and how to weight of each of the measured aspects for calculating final scores of creativity. In that sense, the model is rather flexible and actually enables teachers to adapt it to their teaching goals. In addition, it is suggested to provide students' with an ongoing feedback regarding their progress, preferably through a graphi- cal display of their accomplishments.

Taking all together, it is hoped that with careful planning and implementation, a pedagogic approach that combines problem posing with the proposed model and students' self-assessment of their progress will enhance the teacher's ability to nurture students' creativity and assess its development while taking into account constraints such as coverage of the mandated curriculum and standardized testing outcomes.

There is still, however, a need for a wide scale experiment in order to be able to determine which of the four mentioned aspects of creativity is more likely to be developed through problem posing - that is, subject to observable outside influences, why and how. A wide scale experiment will also enable to deepen the insights regarding the meaning of numerical indicators like averages and standard deviations that can be derive from the model, and the ability to interpret them.

\section{Concluding Remarks}

- This paper neither suggests any conclusive definition of creativity, nor an ultimate approach dictating how to nurture it. Teachers need to be provided with a wide variety of information, tools, and resources in order to enable them to consolidate their world-view regarding these issues, and allow them to decide which approach best suits their teaching goals, educational values and beliefs.

- Given that the final score of creativity does not provide specific information about the scores of each component, one might prefer to display the 4 relative scores and the final score of creativity in a format of a vector such as (R.S fluency, R.S flexibility, R.S originality, R.S organization, overall creativity).

- The problem posing approach, through implementing the WIN strategy, can be adapted to all school disciples, and therefore the proposed model for assessing the development of creativity in the context of problem posing can be employed by teachers from all content areas, and not exclusively by mathematics teachers.

\section{REFERENCES}

Aljughaiman, A., \& Reynolds, E. (2005). Teachers' conceptions of creativity and creative students. Journal of Creative Behavior, 39, 17-34. doi:10.1002/j.2162-6057.2005.tb01247.x

Andiliou, A., \& Murphy, K. P. (2010). Examining variations among researchers' and teachers' conceptualizations of creativity: A review and synthesis of contemporary research. Educational Research Review, 5, 201-219. doi:10.1016/j.edurev.2010.07.003

Balka, D. S. (1974). Creative ability in mathematics. Arithmetic Teacher, 21, 633-363.

Beghetto, R. A. (2006). Creative justice? The relationship between prospective teachers' prior schooling experiences and perceived importance of promoting student creativity. The Journal of Creative Behavior, 40, 149-162. doi:10.1002/j.2162-6057.2006.tb01270.x

Beghetto, R. A., \& Kaufnan, J. C. (2009). Do we all have multicreative potential? ZDM Mathematics Education, 41, 39-44. doi:10.1007/s11858-008-0143-7

Brandau, L. I., \& Dossey, J. A. (1979). Processes involved in mathematical divergent problem-solving. San Francisco: American Educational Research Association.

Brookhart, S., Andolina, M., Zuza, M., \& Furman, R. (2004). Minute math: An action research study of student self-assessment. Educational Studies in Mathematics, 57, 213-227. doi:10.1023/B:EDUC.0000049293.55249.d4

Brown, S. I., \& Walter, M. I. (1969). What if not? Mathematics Teach- 
ing, 46, 38-45.

Brown, S. I., \& Walter, M. I. (1990). The art of problem posing. Hillsdale, NJ: L. Erlbaum Associates.

Chamberlin, S. A., \& Moon, S. (2005). Model-eliciting activities: An introduction to gifted education. Journal of Secondary Gifted Education, 17, 37-47.

Craft, A. (2001). Little c creativity. In A. Craft, B. Jeffrey, \& M. Leibling (Eds.), Creativity in education. London: Continuum.

Craft, A. (2009). Trusteeship, wisdom, and the creative future of education.

http://www.abp.unimelb.edu.au/unesco/ejournal/pdf/craft.pdf

Cunningham, R. (2004). Problem posing: An opportunity for increasing student responsibility. Mathematics and Computer Education, 38, 83-89.

Ellerton, N. F., \& Clarkson, P. C. (1996). Language factors in mathematics teaching and learning. In A. I. Bishop (Eds.), International handbook of mathematics education (pp. 987-1033). Alphen aan den Rijn: Kluwer Academic Publishers.

Enz, B., \& Serafini, F. (1995). Involving students in the assessment process. Teaching PreK-8, 25, 96-97.

Feldman, D. H., \& Benjamin, A. C. (2006). Creativity and education: An American retrospective. Cambridge Journal of Education, 36, 319-336. doi:10.1080/03057640600865819

Fryer, M. (1996). Creative teaching and learning. London: Paul Chapman Publishing Ltd.

Hall, L. D., Fisher, C., Musanti, S., \& Halquist, D. (2006). Professional development in teacher education: What can we learn from PT3? Tech Trends, 50, 25-31. doi:10.1007/s11528-006-7600-3

Haylock, D. W. (1986). Mathematical creativity in schoolchildren. Journal of Creative Behavior, 21, 48-59. doi:10.1002/j.2162-6057.1987.tb00452.x

Henry, J. (2009). Enhancing creativity with M.U.S.I.C. The Alberta Journal of Educational Research, 5, 199-211.

Hönsberger, R. (1985). Mathematical gems III. The Mathematical Association of America.

Lavy I., \& Shriki, A. (2008). Investigating changes in prospective teachers' views of a "Good Teacher” while engaging in a computerized Project-Based-Learning. Journal of Mathematics Teacher Education, 11, 259-284. doi:10.1007/s10857-008-9073-0

Lavy, I., \& Shriki, A. (2010). Engaging in problem-posing activities in a dynamic geometry setting and the development of prospective teachers' mathematical knowledge. Journal of Mathematical Behavior, 29, 11-24. doi:10.1016/j.jmathb.2009.12.002

Leikin, R. (2009). Exploring mathematical creativity using multiple solution tasks. In R. Leikin, A. Berman, \& B. Koichu (Eds.), Creativity in mathematics and the education of gifted students (pp. 129-145). Rotterdam: Sense Publisher.

Lin, Y.-S. (2011). Fostering creativity through education-A conceptual framework of creative pedagogy. Creative Education, 2, 149-
155. doi:10.4236/ce.2011.23021

Mann, E. L. (2006). Creativity: The essence of mathematics. Journal for the Education of the Gifted, 30, 236-260.

Martinez-Cruz, A. M., \& Contreras, J. N. (2002). Changing the goal: An adventure in problem solving, problem posing, and symbolic meaning with a TI-92. Mathematics Teacher, 95, 592-597.

NACCCE (1999). All our futures: Creativity, culture and education, national advisory committee on creative and cultural education. London: DFEE.

http://www.cypni.org.uk/downloads/alloutfutures.pdf

NCTM-National Council of Teachers of Mathematics (2000). Principles and standards for school mathematics. Reston, VA: NCTM.

Plucker, J. A., Beghetto, R. A., \& Dow, G. T. (2004). Why isn't creativity more important to educational psychologists? Potential, pitfalls, and future directions in creativity research. Educational Psychologists, 39, 83-96. doi:10.1207/s15326985ep3902_1

Reid, A., \& Petocz, P. (2004). Learning domains and the process of creativity. The Australian Educational Researcher, 31, 45-62. doi:10.1007/BF03249519

Rowlands, S. (2011). Disciplinary boundaries for creativity. Creative Education, 2, 47-55. doi:10.4236/ce.2011.21007

Shalley, C. E., \& Gilson, L. L. (2004). What leaders need to know: A review of social and contextual factors that can foster or hinder creativity. Leadership Quarterly, 15, 33-53. doi:10.1016/j.leaqua.2003.12.004

Shriki, A. (2010). Working like real mathematicians: Developing prospective teachers' awareness of mathematical creativity through generating new concepts. Educational Studies in Mathematics, 73, 159179. doi:10.1007/s10649-009-9212-2

Silver, E. A. (1994). On mathematical problem posing. For the Learning of mathematics, 14, 19-28.

Silver, E. A. (1997). Fostering creativity through instruction rich in mathematical problem solving and problem posing. ZDM-The International Journal on Mathematics Education, 29, 75-80. doi:10.1007/s11858-997-0003-X

Smith, C. (1997). Student self-assessment at St. Bernadette's primary school. Primary Educator, 3, 7-9.

Sriraman, B. (2005). Are giftedness and creativity synonyms in mathematics? The Journal of Secondary Gifted Education, 17, 20-36.

Stoyanova, E., \& Ellerton, N. F. (1996). A framework for research into students' problem posing. In P. Clarkson (Ed.), Technology in mathematics education (pp. 518-525). Melbourne: Mathematics Education Research Group of Australasia.

Torrance, E. P. (1974). The torrance tests of creative thinking: Technical-norms manual. Bensenville, IL: Scholastic Testing Services.

Treffinger, D. J., Young, G. C., Selby, E. C., \& Shepardson, C. (2002). Assessing creativity: A guide for education. Sarasota, FL: The National Research Center on the gifted and talented. 